\title{
MICROORGANISMS FOUND IN THE TANNERY AIR
}

\author{
CORINA CHIRILĂ, MARIANA DANIELA BERECHET \\ INCDTP - Division Leather and Footwear Research Institute, 93 Ion Minulescu st., sector 3, RO- \\ 031215 Bucharest, corina.chirila@icpi.ro
}

\begin{abstract}
Past research has shown that there may be different types of microorganisms in the tannery air These microorganisms can be harmful for the health of the employees and for the leather. Pathogenic bacteria in genus Staphylococcus, Bacillus, Pseudomonas, Enterobacter, Nocardiopsis and other putrefaction microorganisms and fungi that can damage the leather enter the tannery with the raw hides. During the experiment, a Petri plate with Sabouraud culture medium was exposed to the tannery air, being kept open for 13 minutes in the wet operations area of a tannery. After incubation at $30^{\circ} \mathrm{C}$, the plates were analyzed after 3, 4, 5, 6 and 7 days for the identification of the microorganisms in the air. At the end of the experiment the mould colonies that have grown were analysed using the optical microscope. Multiple colonies of Penicillium and a colony of Aspergillus flavus have grown on the nutrient medium. Our experiment proved that there are spores of Penicillium and Aspergillus flavus in the tannery air. These moulds can damage the leather and Aspergillus flavus produces afflation, being harmful for the health.
\end{abstract}

Keywords: tannery, aerosols, fungal spores

\section{INTRODUCTION}

Bio aerosols are living particles in the air, such as viruses, bacteria, fungi and even mites and pollen grains (Deselnicu et al., 2005). Regarding the size of the particles, these are very small and vary from less than one micrometer to 100 micrometers. Bio aerosols react to the air flow, moving fast or slow depending on environmental factors such as air density or gravity. Bio aerosols can lead to the spreading of atypical and very severe diseases.

The tannery air contains microorganisms from the hides (Deselnicu et al., 2005; Deselnicu et al., 2007; Chirila et al., 2014), from the workers or from the external environment. With the raw hide, bacteria in genus Staphylococcus, Bacillus, Pseudomonas, Enterobacter, Nocardiopsis and other putrefaction microorganisms enter the tannery air (Daliborca, 2009).

From the past research is known that the tannery workers can inhale diverse types of biological agents, most of them bacteria (50-92\%) (Skóra et al., 2014).

The species Acinetobacter calcoaceticus, Acinetobacter johnsonii, Nocardiopsis dassonvillei, Pantoea agglomerans, Pseudomonas putida, Staphylococcus gallinarum, Bacillus pumilus, Bacillus subtilis, Bacillus cereus, Corynebacterium lubricantis, Cladosporium cladosporioides, Penicillium commune, Penicillium echinulatum, Penicillium chrysogenum, Penicillium crustosum, Candida parapsilosis and Cryptococcus albidus have been identified in the tannery air (Skóra et al., 2014; Castellanos-Arévalo et. al., 2016).

Acinetobacter calcoaceticus is a gram-positive aerobic coccobacillus which can be found in the human intestinal flora and can cause opportunistic infections in immunecompromised patients.

Nocardiopsis dassonvillei is an aerobic bacterium in the Actinomicetae group which lives in the soil where animals are grown, in the marine sediments and other natural mediums, but it can be pathogenic causing shin and lung infections. The bacterium produces resistance spores and a branched mycelium. Nocardiopsis dassonvillei can decompose adenine, casein, tyrosine, xanthan, hypoxanthine, gelatin and urea. The 
bacteria can hardly be identified, being necessary to analyze the fat acids in the cell wall and ARNr 16S s sequencing (Beau et al.,1999; Sun et al., 2010).

Pantoea agglomerans or Enterobacter agglomerans is a gram-negative bacteria in the Enterobacteria family and it can cause opportunistic infections in immunecompromised patients. The bacteria are found commonly on the substrate plant (leaves, seeds or fruits) and faces. The bacteria is hard to be differentiated from the genus Enterobacter, Klebsiella and Serratia, the only difference being the fact it does not use the amino acids lysine, arginine and ornithine. This bacterium is part of the intestinal flora grasshoppers and mosquitoes, the latter being protected from malaria by this bacterium.

Pseudomonas putida is a gram-negative rod shaped bacteria that can be found in the soil. This bacteria can degrade toluene and other organic solvents, which makes it useful for the soil bioremediation. It can rarely cause infections, but a lethal case has been reported in a malnourished paralyzed patient with peripheral circulatory problems (Thomas et al., 2013; https://microbewiki.kenyon.edu/).

Staphylococcus gallinarum is a gram-positive bacteria which, like Staphylococcus aureus, forms grape like structures, and that is why it is called staphylococcus (Gr. Staphylo = grape). The bacterium was first identified in chickens and pheasants but is present in human saliva. Although usually not pathogenic, bacteria were found in infected wounds of patients in hospitals and in a patient with hepatitis B (CastellanosArévalo et. al., 2016).

Bacillus pumillus is a gram-positive aerobic bacterium which lives in the soil, near the roots of plants, forming spores. The bacteria can stop the growth of other bacteria or fungi due to some plasmid genes (Castellanos-Arévalo et. al., 2016).

Bacillus subtilis called the grass bacillus is a gram-positive bacteria that lives in the soil and in the animal gut. The bacteria measures 4-10 m length and 0.25-1.0 m diameter and shows flagella that can move. The optimum temperature for bacterial growth is between 25 and $35^{\circ} \mathrm{C}$, but it can resist in extreme conditions due to its ability to form endospores. The genome of this species consists of approximately 4,100 genes (Castellanos-Arévalo et. al., 2016).

Bacillus cereus is a gram-positive $\beta$-hemolytic bacteria which lives in the soil. Some strains are pathogenic while others are benefic for the animals. At $30^{\circ} \mathrm{C}$, a Bacillus cereus population can double in 20 minutes to 3 hours, depending on the substrate. Like other species of the Bacillus genus, Bacillus cereus can cause endospores resistance. In 2006 in this species were discovered enzymes involved in AlkD AlkC and DNA repair. In the intestine, Bacillus cereus is in competitive relationship with Salmonella and Campylobacter, and its presence reduces the number of these bacteria. Bacillus cereus is used to inhibit the replication of Salmonella bacteria in the intestine and cecum in birds, rabbits and pigs (Skóra et al., 2014).

Cladosporium cladosporioides is a dark colored mold which can grow on many types of materials and it can be often found in the air, its spores can cause allergies. The fungus is not pathogenic for humans and animals, but it is harmful for plants, attacking the leaves and the fruits. Species asexually reproduce by spores form branched chain and can grow in conditions of low humidity and very low temperatures (Lewis et al., 2005).

Penicillium commune is a fungus that grows on dry meat and some cheeses and it produces toxins such as cyclopiazonic acid, rugulovasin and viridicatin. 
ICAMS $2016-6^{\text {th }}$ International Conference on Advanced Materials and Systems

Penicillium echinulatum is a fungus in the genus Penicillium which produces celulases, 5-Hydroxymaltol and mycophenolic acid.

Penicillium chrysogenum is a mold in the genus Penicillium living in temperate areas and subtropical areas, resistant in high salinity conditions, which can develop on salted food. This mold can develop inside buildings where there is high humidity. There have been isolated cases where this species was pathogenic to humans. Penicillium chrysogenum $\beta$-lactam antibiotics produce penicillin is the best known of these antibiotics. Penicillium chrysogenum was used in the pharmaceutical industry to produce penicillin. Penicillium glaucum and Penicllium Rubens and they produce penicillin and were used in early research for getting antibiotics. In 1928 Alexander Fleming discovered Penicillium Rubens that can inhibit the growth of Staphylococcus aureus colonies with bactericidal effect. Like other species of Penicillium, Penicillium chrysogenum reproduces by spores (conidia) that form long chains on the conidiophores form of brush. The color is blue-green colonies with areas where there is a yellow pigment. This yellow pigment gives the name of the species. In ancient Greek chrysos means gold (Lewis et al., 2005).

Penicillium crustosum is a mold in the genus Penicillium found frequently in the places populated by humans, in soil and on some food products. Some strains produce neurotoxins while others produce penicillin. The colonies have a dark bluish green color, they grow fast and have a crust made of conidia (Moldes-Anaya et al., 2012).

Candida parapsilosis is a yeast similar to Candida albicans that can cause infections in immune-compromised patients with open wounds. In contrast, Candida parapsilosis is not pathogenic for immune-compromised patients than being a commensal to the human species, seen most often in the skin on the hands. In patients with low immunity Candida parapsilosis can cause onychomycosis. The species mentioned above can cause nosocomial infections, being present in hospitals. This species grows naturally in soil or parasitic insects and various animals (Castellanos-Arévalo et. al., 2016).

Cryptococcus albidus is a fungus that can grow on human skin, the vagina or in the lungs, which can cause ringworm. On Sabouraud culture medium colonies have a smooth, glossy, creamy-white specific yeast colonies. Under the microscope, appearance of the yeast as globular or ovoid blast conidia can be observed (http://www.mycology.adelaide.edu.au/Fungal_Descriptions/Yeasts/Cryptococcus/C_al bidus.html).

In this study we aimed to highlight the pathogenic microorganisms in the air of a tannery that processes cattle leather in wet operations - soaking, liming, deliming to tanning.

\section{MATERIALS AND METHODS}

\section{Data Regarding the Wet Operations Workplace}

Built by the year: 1951; Surface: $100 \mathrm{~m}^{2}$; Volume: $500 \mathrm{~m}^{3}$; No. of workers: 5 ; Ventilation: natural; Temperature: $24^{\circ} \mathrm{C}$; Humidity of the air: $60 \%$.

\section{Method}

A Petri plate with Sabouraud culture medium has been left open for 13 minutes in a tannery in the wet operations area, and then it has been put into the incubator at $30^{\circ} \mathrm{C}$ and analyzed after 3, 4, 5, 6 and 7 days to identify the microorganisms grown on the 
plate. The samples have been analyzed using an optic microscope Biolux NV BRESSER la Magnitude 100.

\section{RESULTS}

\section{Identification of the Microorganisms}

The samples were tracked daily on colony growth to 7 days, after which they were analyzed with light microscopy to identify them. After 3 days colonies of microorganisms first appeared. Two colonies of fungi spore began, and after four days, most colonies began to spore.

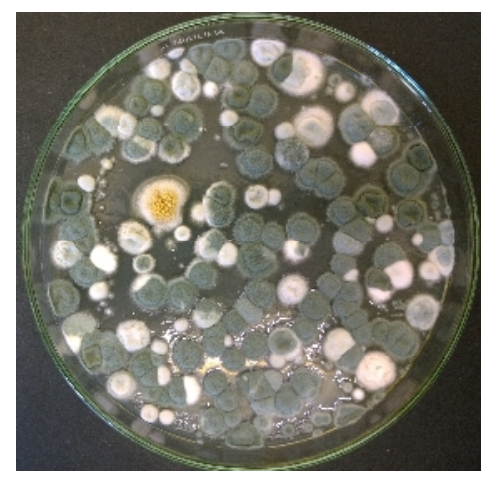

Figure 1. Colonies appeared on the Sabouraud culture medium after 7 days

Penicillium colonies predominated, but an Aspergillus flavus colony appeared isolated, the first colony that sporulated. Aspergillus flavus colony presented a large number of bodies of fructification, even after 3 days from the beginning of the experiment when other colonies did not start sporulation at all.

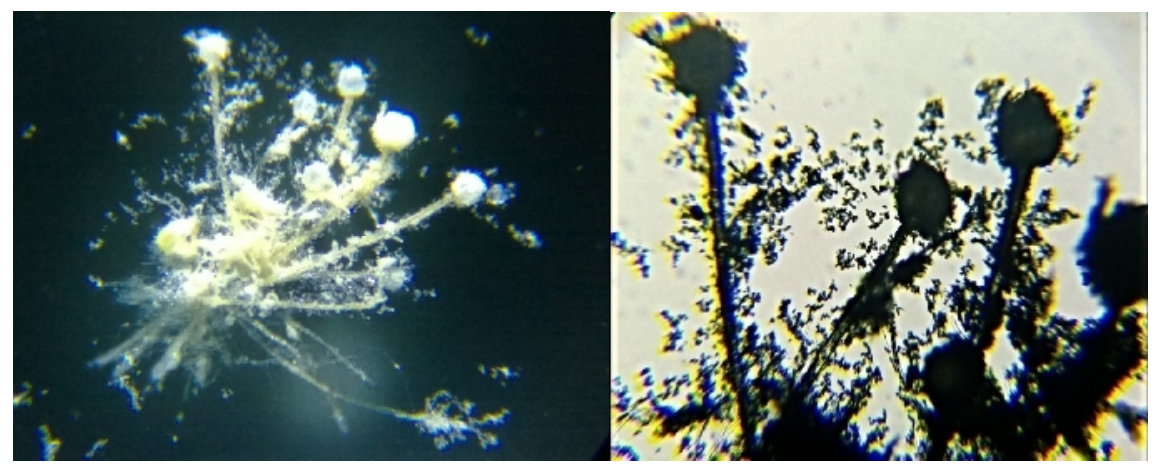

Figure 2. Aspergillus flavus (magnitude 100) 
ICAMS $2016-6^{\text {th }}$ International Conference on Advanced Materials and Systems

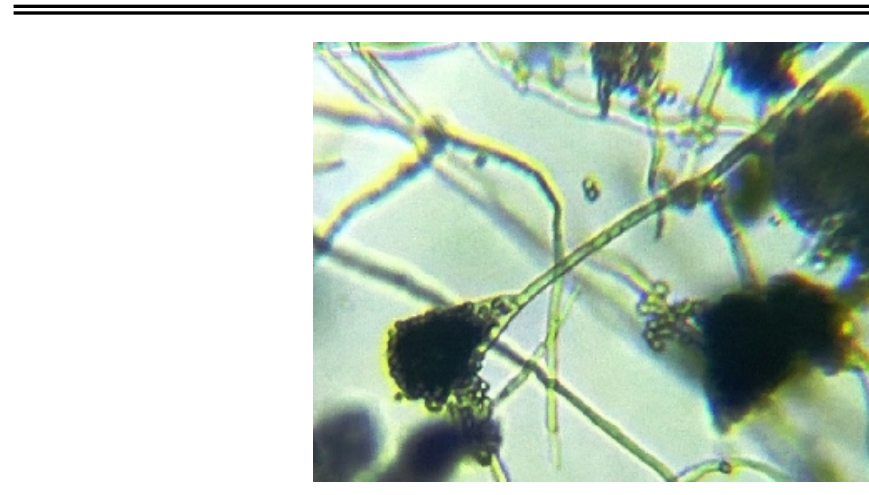

Figure 3. Penicillium (magnitude 100)

Aspergillus flavus is one of the 180 species of the genus Aspergillus, is akin to Aspergillus niger and Aspergillus fumigates. Aspergillus flavus mold saprophyte is widespread in the environment that can grow in soil and on certain plants or animals even if they are in a state of immune-suppression. Aspergillus flavus develops very quickly on cereal, vegetables and on various food products stored in improper conditions. Colonies are yellow or yellow-green, depending on the strain. The spores develop on conidiophores form globular features like Aspergillus.

Besides the fact that it can be allergen and pathogen for immune-compromised patients, Aspergillus flavus produces a toxin and carcinogen afflation.

Aspergillus flavus colonies sporulated faster than those of the species of the genus Penicillium. The species of the genus Aspergillum have an invasive and aggressive nature certainly developing rapidly at the expense of other species. This phenomenon was observed in colony-forming Aspergillus niger growing even faster than the Aspergillus flavus and in less than seven days covering the entire surface of the culture medium, leaving no space for other species.

\section{CONCLUSIONS}

In the tannery air Penicillium spores are predominant, harmless for the human health, but harmful for the leather which can be deteriorated by this mold; there is also Aspergillus flavus, which is harmful for the objects that may be degraded by this mold and also for the human health because it produces afflation.

Results indicate that potential health risks arise from the fungal small bio aerosol particles presence in relation to the outdoor air.

\section{Acknowledgements}

This study has been funded by ANCSI in the framework of the program NUCLEU 2016-2017, project code PN 163402 05, contract 26/14.03.2016.

\section{REFERENCES}

Beau, F., Bollet, C., Coton, T., Garnotel, E. and Drancourt, M. (1999), "Molecular Identification of a Nocardiopsis dassonvillei, Blood Isolate", Journal of Clinical Microbiology, 37(10), 3366-3368.

Castellanos-Arévalo, A.P., Camarena-Pozos, D.A., Castellanos-Arévalo, D.C., Rangel-Córdova, A.A., PeñaCabriales, J.J., Arévalo-Rivas, B., Guzmán de Peña, D. and Maldonado-Vega, M. (2016), "Microbial 
contamination in the indoor environment of tanneries in Leon, Mexico", Indoor and Built Environment, 25(3), 524-540.

Chirila, C., Crudu, M. and Deselnicu, V. (2014), "Comparative study regarding resistance of wet-white and wet-blue leather to the growth of fungi", Leather and Footwear Journal, 14(2), 107-120.

Chirila, C., Crudu, M. and Deselnicu, V. (2014), "Study regarding the resistance to the growth of fungi of wet-white leather tanned with Titanium - Aluminum", Proceedings of The 5th ICAMS 2014, 23-25 October 2014, Bucharest, 31-36.

Chirila, C., Deselnicu, V. and Crudu, M. (2014), "Study regarding the resistance of wet-white leather organic tanned to the growth of fungi", Proceedings of The 5th ICAMS 2014, 23-25 October 2014, Bucharest, 37 42.

Daliborca, C.V. (2009), "Determination of species and number of pathogens in the air inside public buildings and education institutions in Timisoara", available at: http://www.dmmt.ro/uploads/files/proiecte\%20si\%20studii/Aeroflora_2.pdf

Deselnicu, V., Maier, S.S., Deselnicu, O.C. and Florescu, M. (2005), "Impact of technological changes on increased health and comfort efficiency", Proceedings of The $4^{\text {th }}$ International Conference in Management of Technological Change, Book 1, Chania, Greece, 19-20 August, 87-92.

Deselnicu, V., Maier, S.S., Albu, L. and Buruntea, N. (2007), "Antimicrobial and antifungal leathers for increasing the health and the comfort of the individuals", CORTEP, 18-21 Oct., Iasi, RO.

Lewis, P.R., Donoghue, M.B., Cook, L., Granger, L.V. and Hocking, A.D. (2005), "Tremor syndrome associated with a fungal toxin: sequelae of food contamination", Medical Journal of Australia, 182(11), 582-584.

Moldes-Anaya, M., Rundbergetc, T., Fæstec, C.K., Eriksenc, G.S. and Bernhoft, A. (2012), "Neurotoxicity of Penicillium crustosum secondary metabolites: Tremorgenic activity of orally administered penitrem A and thomitrem A and E in mice", Toxicon, 60(8), 1428-1435.

Skóra, J., Gutarowska, B., Stepień, Ł., Otlewska, A. and Pielech-Przybylska, K. (2014), “The evaluation of microbial contamination in the working environment of tanneries", Medycyna pracy, available at http://www.ncbi.nlm.nih.gov/pubmed/24834690.

Sun, H., Lapidus, A., Nolan, M., Lucas, S., Del Rio, T.G., Tice, H., Cheng, J.F., Tapia, R., Han, C., Goodwin, L., Pitluck, S., Pagani, I., Ivanova, N., Mavromatis, K., Mikhailova, N., Pati, A., Chen, A., Palaniappan, K., Land, M., Hauser, L., Chang, Y.J., Jeffries, C.D., Djao, O.D., Rohde, M., Sikorski, J., Göker, M., Woyke, T., Bristow, J., Eisen, J.A., Markowitz, V., Hugenholtz, P., Kyrpides, N.C. and Klenk, H.P. (2010), "Complete genome sequence of Nocardiopsis dassonvillei type strain (IMRU 509)", Standards in Genomic Sciences, 3(3), 325-36, doi: 10.4056/sigs.1363462.

Thomas, B., Okamoto, K., Bankowski, M.J. and Seto, T.B. (2013), "A Lethal Case of Pseudomonas putida Bacteremia Due to Soft Tissue Infection”, Infectious Diseases in Clinical Practice (Baltimore, MD), 21(3), 147-213, doi: 10.1097/IPC.0b013e318276956b.

*** http://www.mycology.adelaide.edu.au/Fungal_Descriptions/Yeasts/Cryptococcus/C_albidus.html 